\title{
Rapid glutamate receptor 2 trafficking during retinal degeneration
}

\author{
Yanhua Lin, Bryan W Jones, Aihua Liu, Félix R Vazquéz-Chona, J Scott Lauritzen, W Drew Ferrell and Robert E Marc ${ }^{*}$
}

\begin{abstract}
Background: Retinal degenerations, such as age-related macular degeneration (AMD) and retinitis pigmentosa (RP), are characterized by photoreceptor loss and anomalous remodeling of the surviving retina that corrupts visual processing and poses a barrier to late-stage therapeutic interventions in particular. However, the molecular events associated with retinal remodeling remain largely unknown. Given our prior evidence of ionotropic glutamate receptor (iGluR) reprogramming in retinal degenerations, we hypothesized that the edited glutamate receptor 2 (GluR2) subunit and its trafficking may be modulated in retinal degenerations.

Results: Adult albino Balb/C mice were exposed to intense light for $24 \mathrm{~h}$ to induce light-induced retinal degeneration (LIRD). We found that prior to the onset of photoreceptor loss, protein levels of GluR2 and related trafficking proteins, including glutamate receptor-interacting protein 1 (GRIP1) and postsynaptic density protein 95 (PSD-95), were rapidly increased. LIRD triggered neuritogenesis in photoreceptor survival regions, where GluR2 and its trafficking proteins were expressed in the anomalous dendrites. Immunoprecipitation analysis showed interaction between KIF3A and GRIP1 as well as PSD-95, suggesting that KIF3A may mediate transport of GluR2 and its trafficking proteins to the novel dendrites. However, in areas of photoreceptor loss, GluR2 along with its trafficking proteins nearly vanished in retracted retinal neurites.
\end{abstract}

Conclusions: All together, LIRD rapidly triggers GluR2 plasticity, which is a potential mechanism behind functionally phenotypic revisions of retinal neurons and neuritogenesis during retinal degenerations.

Keywords: glutamate receptor 2, retinal degeneration, retinal remodeling, neuritogenesis

\section{Background}

Retinal degenerations (RD), such as age-related macular degeneration (AMD) and retinitis pigmentosa (RP), are progressive disorders initiated by photoreceptor stress and are accelerated by photoreceptor death, which effectively deafferents the inner retina and evolves into formal retinal remodeling [1-3]. Thus, retinal remodeling proceeds through three phases: 1 , photoreceptor stress; 2 , photoreceptor death and 3, complex neural remodeling [3]. Two of the major hallmarks of retinal remodeling are growth of novel neurites and functional reprogramming of existing retinal neurons [1-8]. Pathogenic neuronal reprogramming and de novo neuritogenesis are not isolated to retinal tissues, as pathological revision also occurs in neurodegenerative diseases such as epilepsy [9] and Alzheimer's

\footnotetext{
* Correspondence: robert.marc@hsc.utah.edu

Department of Ophthalmology, John A. Moran Eye Center, University of Utah School of Medicine, 65 Mario Capecchi Drive, Salt Lake City, UT 84132, USA
}

(c) 2012 Lin et al; licensee BioMed Central Ltd. This is an Open Access article distributed under the terms of the Creative Commons Attribution License (http://creativecommons.org/licenses/by/2.0), which permits unrestricted use, distribution, and reproduction in any medium, provided the original work is properly cited. disease [10]. Retinal remodeling limits the effectiveness of vision rescue strategies including photoreceptor- and retinal pigment epithelium (RPE)-directed therapies $[4,6,7,11,12]$. Better understanding of the mechanisms underlying retinal remodeling will improve the outcomes of genetic, molecular, cellular and bionic rescues.

Deafferentation of the neural retina eliminates the intrinsic glutamatergic drive by the sensory retina [3] and induces glutamate receptor reprogramming before gross topologic restructuring of the retina begins $[4,13]$. In phase 2 degenerating retinas with extensive rod death, the downstream rod-specific signaling pathways persists [13,14], and bipolar cells still respond to glutamate receptor agonists $[4,7,15]$. Among the glutamate receptors (GluRs), $\alpha$-amino-3-hydroxy-5-methyl-4-isoxazolepropionic acid (AMPA) receptors mediate fast synaptic transmission at excitatory synapses in CNS and are tetrameric assemblies of subunits GluR1-4 encoded by separate genes [16]. Their involvement and

\section{() Biomed Central}


modulation during neuronal development, synaptic plasticity and structural remodeling is fundamental to timing and coherence of developing neural networks [17]. In brain, combined neuronal activity and pathologic insults trigger rapid changes in postsynaptic AMPA receptor attributes (e.g. subunit composition) and may control $\mathrm{Ca}^{2+}$ permeability [18]. $\mathrm{Ca}^{2+}$ fluxes play critical roles in neural function, including the regulation of neurite outgrowth and synaptogenesis [19], synaptic transmission and plasticity [20], and cell survival [21]. GluR2 in heteromeric AMPARs renders the channel low permeable to $\mathrm{Ca}^{2+}[22,23]$, so that even a modest alteration in the level of GluR2 is expected to have profound implications for synaptic efficacy and neuronal survival [24].

Given prior evidence of iGluR reprogramming in human RP and animal models of RD $[4,8,25]$, we hypothesized that retinal iGluRs, especially GluR2 subunits are modulated in retinal degenerative diseases. GluR2 subunit expression is associated with vertical channel retinal processing [26-28], and its expression limits AMPAR permeability to $\mathrm{Ca}^{2+}[29]$. In this sense it is thought to be neuroprotective [30,31]. To study the kinetics of GluR2 expression and trafficking in retinal degenerative disease, we used the LIRD model, which contains the full spectrum of sequelae found in naturally occurring and engineered forms of retinal degeneration and remodeling, including early retinal stress, photoreceptor loss, Müller cell remodeling, neuritogenesis [8], and remodeling of all neural cell populations in the retina and formation of microneuromas $[8,12]$. Our analysis of glutamate receptors and neuritogenesis in the light-damage model spans phases 1 and 2 . This work demonstrated that in a LIRD model, GluR2 levels and trafficking rapidly increased in response to light-induced photoreceptor stress and death, providing a potential feedback mechanism for controlling $\mathrm{Ca}^{2+}$ permeability in retinal neurons. Most importantly, GluR2 upregulation may occur in ON bipolar cells, which are normally hyperpolarized by glutamate. Expression of AMPA receptors would change their polarity as predicted by Marc et al 2007 [4] and Jones et al. [13] in mouse, rabbit and human retina. In addition, the motor protein KIF3A colocalized well with PSD-95 and GRIP1 at novel sprouting neurites, potentially indicating a chaperone role for KIF3A, guiding GluR2 and its trafficking proteins to newly forming dendritic processes.

\section{Results}

LIRD increases GluR2 expression prior to obvious

\section{photoreceptor loss}

LIRD led to dramatic photoreceptors loss by post-light exposure day 7 (pLX7) (Figure 1A), demonstrating that LIRD is a "fast degenerating" animal model of retinal degeneration [32]. Consistent with our previous results
$[8,12]$, light stress differentiated the mouse retina into survivor zones, where stressed photoreceptors and retinal neurons persisted, and light-damage zones, where rods and cones died (Figure 1B). Despite that DAPI staining showed a normal thickness of inner nuclear layer (INL) in both the survivor and light-damage zones and histological analysis of retina revealed normal lamination and topology at light onset (pLX0) through pLX1 (Figure 1A and 1B), protein levels of GluR2 showed immediate response to light stress. Specifically, protein levels of GluR2 increased immediately at pLX0, peaked at $\mathrm{pLX} 7$, and recovered to almost control levels by pLX30 (Figure 1C and 1D). GluR2 immunostaining of control tissues (postnatal day 80) revealed GluR2-immunoreactive puncta aggregating in the outer plexiform layer (OPL) with more GluR2-immunoreactive puncta found throughout the OFF and ON sublamina (Figure $1 \mathrm{E})$.

\section{GluR2 trafficking protein levels are modulated during LIRD}

GluR2 is assembled, with other GluR subunits, into iGluR channels in the postsynaptic membrane [33]. The C-terminus of GluR2 contains a PDZ domain that binds GluR2 to trafficking proteins including GRIP1, ABP, PICK1 [34-36], and stargazin [37]. GluR2 is anchored at synaptic and intracellular membranes by ABP/GRIP but cycles between these membranes in association with PICK1 [38]. Consistent with a previous report [39], PSD-95 was most prominent in the rod spherules and cone pedicles of the OPL, weak PSD-95 labeling was also present in the inner plexiform layer (IPL) (Figure $2 \mathrm{~A}$ ). The retinal distributions of GluR2 trafficking proteins GRIP1, ABP, PICK1 and stargazin showed labeling in the OPL and IPL (Figure 2B-E). These data confirm the presence of GluR2-related PSD proteins such as $\mathrm{ABP}$ and GRIP1 in the retina as demonstrated by Gabriel et al [40]. Similar to findings in GluR2 protein expression, PSD-95, GRIP1, ABP, and stargazin expression were increased by light stress, levels of PSD-95, ABP, and GRIP1 peaked at pLX1 and then recovered, while the levels of stargazin were elevated from pLX1 to pLX30, the last time point in the experiment (Figure 2F and 2G). Protein levels of PKC $\alpha$ and PICK1 were unaltered by light exposure from pLX1 to pLX30 (Figure 2F and 2G). Western blotting images of PSD-95 protein levels revealed three adjacent bands (Figure 2F), potentially due to that the anti-PSD-95 IgG targets a common epitope in the homologous regions [39].

\section{LIRD triggers neuritogenesis by rod bipolar cells and horizontal cells in the survivor zone}

In control retinas, $\mathrm{PKC} \alpha$ staining revealed fine, bushy dendritic processes of rod bipolar cells only in the OPL 


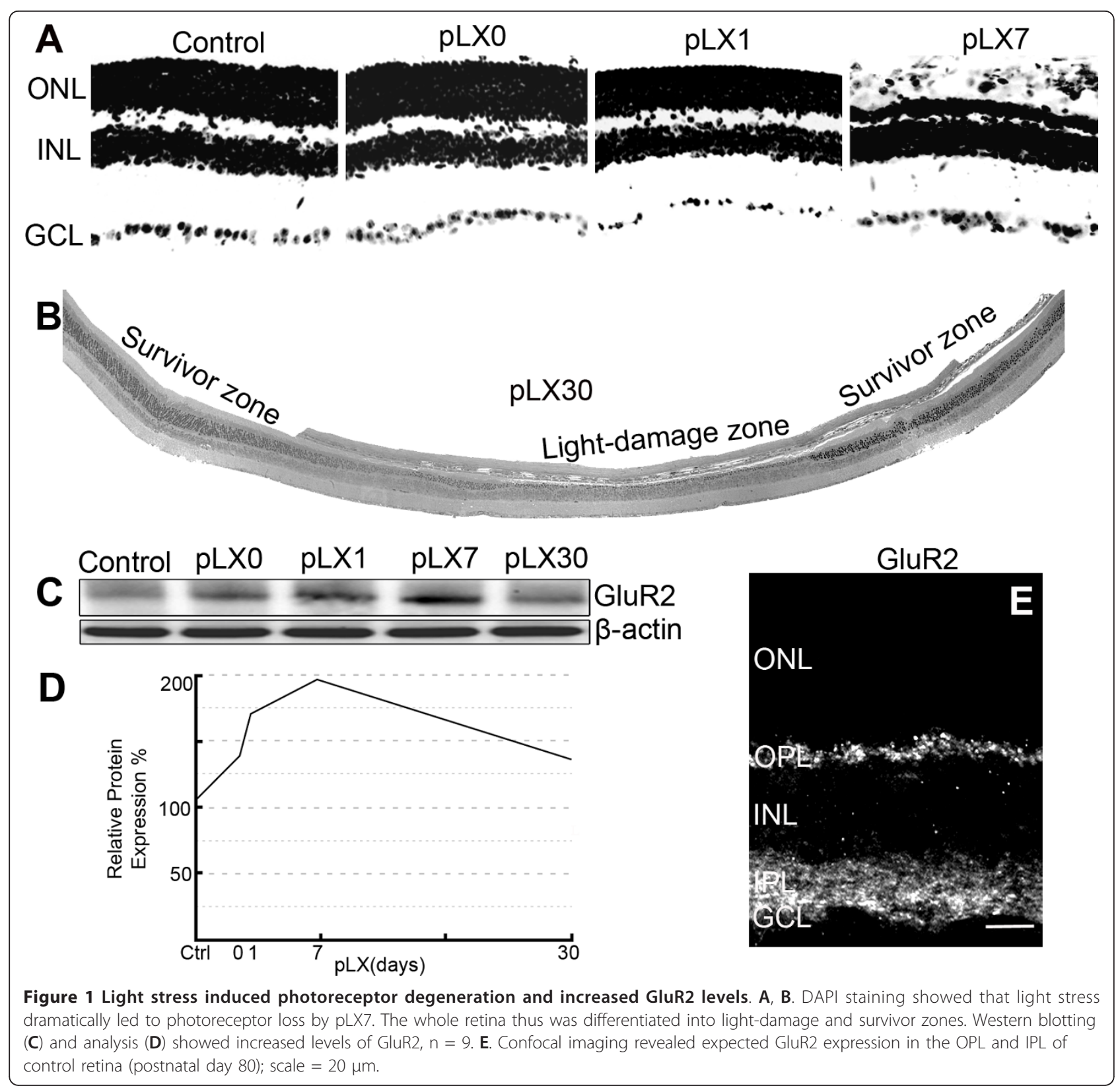

(Figure 3A), while rod bipolar cells in LIRD retinas exhibited dramatic neuritogenesis occurring by pLX7 in the survivor zone (data not shown) and becoming more obvious by pLX30. Rod bipolar cells in the LIRD retinas extended their dendrites from the OPL into outer nuclear layer (ONL) (Figure 3B and 3B', highlighted by arrows) in the survivor zone. Further, calbindin immunostaining revealed calbindin-positive horizontal cells undergoing similar neuritogenesis. While neurites of horizontal cells were confined in the OPL in the control retina (Figure $3 \mathrm{C}$ ), horizontal cells in the LIRD retinas extended their neurites from the OPL into the ONL in the survivor zone (Figure 3D and 3D', highlighted by arrows). These findings are consitent with the formation of novel neurites found in human RP, AMD and animal models of retinal degenerations [5,6,13,41-43].

GluR2 and its trafficking proteins are expressed in the new neurites in the survivor zone

We correlated the findings of neuritogenesis here with alterations in GluR2 trafficking. Examination of expression patterns of GluR2 and its trafficking proteins in new neurites demonstrated that GluR2, PSD-95, stargazin, PICK1, GRIP1 and ABP were present in the OPL as well as in the ONL during LIRD (Figure 4A-F). GluR2 partially co-localized with PKC $\alpha$ in the new neurites 


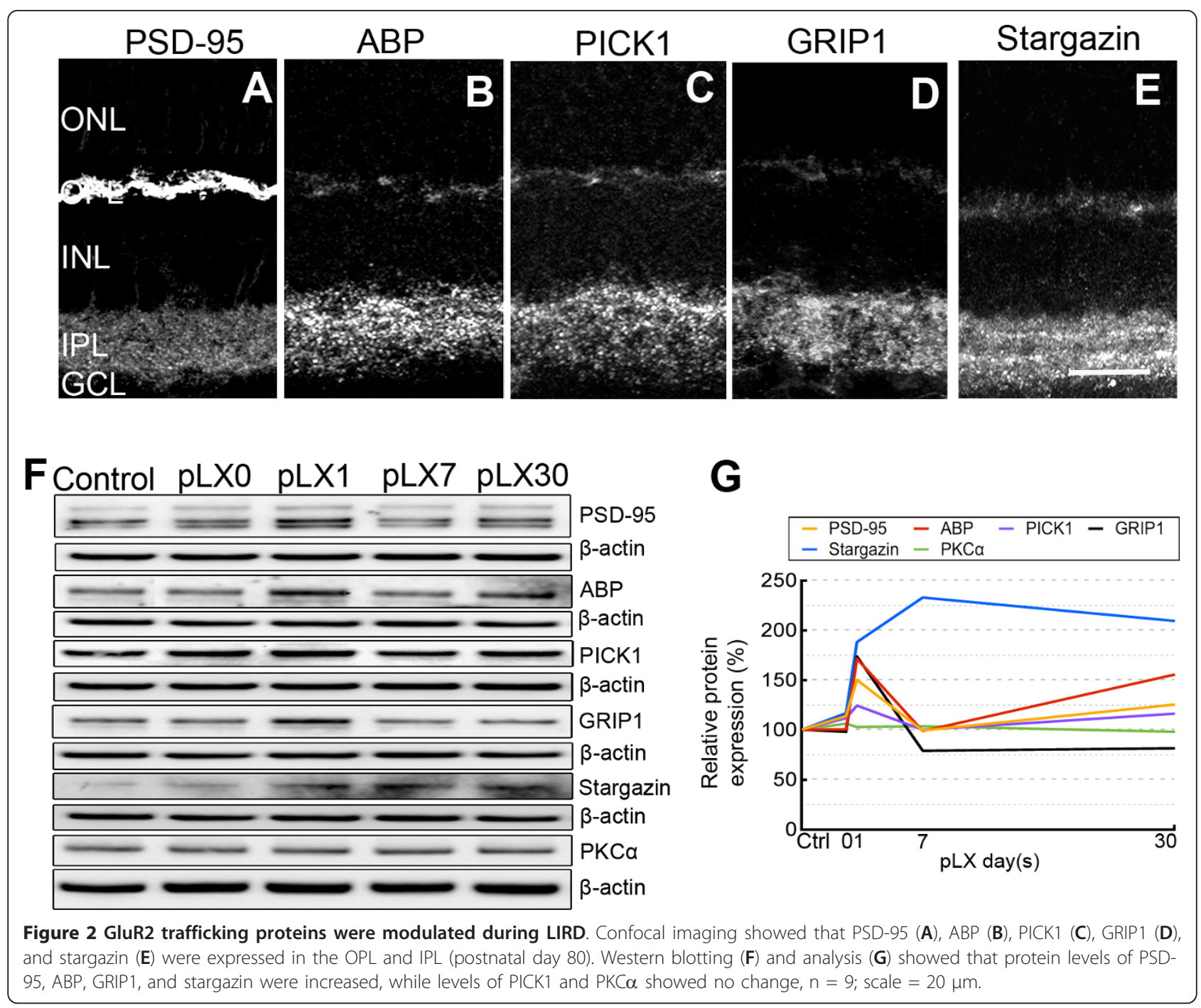

(Figure 4A), suggesting that GluR2 is expressed in the new neurites of rod bipolar cells during retinal degenerations. Different from PKC $\alpha$, PSD-95 co-localized well with GluR2 in the new neurites in the ONL (Figure 4B). GluR2 also co-localized well with PICK1 (Figure 4C), GRIP1 (Figure 4D), stargazin (Figure 4E), and ABP (Figure $4 \mathrm{~F}$ ) in the new neurites in the ONL. These data are consistent with the data proposing PSD-95, stargazin, PICK1, GRIP1 and ABP as anchoring of GluR2 at synaptic locations [44].

KIF3A interacts with GRIP1 and PSD-95 in mouse retina KIF3A is a reported motor protein expressed at the basal body of the connecting cilium axoneme and at the synaptic ribbons of cones and rods [45]. Our data showed that KIF3A was expressed in the OPL and IPL of control retina (Figure 5A), thereby raising the possibility that KIF3A interacts with postsynaptic density proteins which are also present in the OPL and IPL. Protein expression of KIF3A during LIRD was relatively stable, with a slight decrease on pLX7 (Figure 5B). Interactions between KIF3A and GRIP1 and PSD-95 were demonstrated by immunoprecipitation analysis (Figure 5C). During LIRD, KIF3A was also expressed in the new neurites, where KIF3A co-localized well with PSD-95 (Figure 5D) and GRIP1 (Figure 5E), suggesting that KIF3A may be involved in guiding GluR2 and its trafficking protein to the new dendrites.

GluR2 and its trafficking proteins are lost in the lightdamage zone

In contrast to the survivor zone, GluR2 expression disappeared by pLX30 in the light-damage zone, where only one layer of photoreceptors was left (Figure 6A). The expression of PSD-95 was also dramatically decreased in the light-damage zone (Figure 6B). Similar 


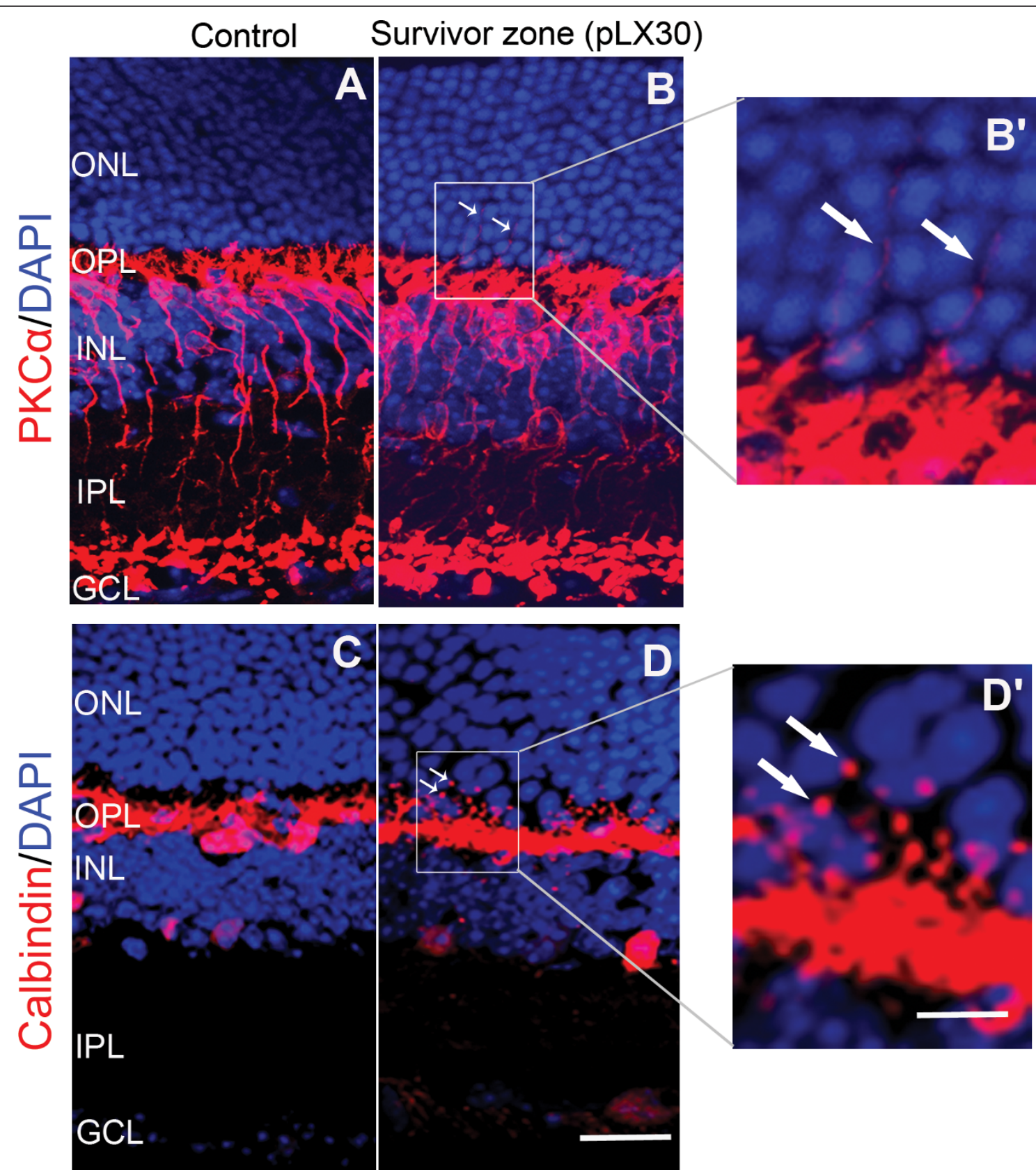

Figure 3 LIRD induced retinal neuritogenesis. A, B. PKC $\alpha$ immunohistochemistry revealed that LIRD induced neuritogenesis by rod bipolar cells, with dendrites extending from the OPL into the ONL (highlighted by arrows). C, D. Calbindin immunohistochemistry showed neuritogenesis by horizontal cells with processes extending from the OPL into the ONL in the survivor zone (highlighted by arrows). B' and D' are high magnification views of the rectangular areas in $B$ and $D$, scale $=15 \mu \mathrm{m}(\mathbf{A}-\mathbf{D})$ or $6 \mu \mathrm{m}\left(\mathbf{B}^{\prime}, \mathbf{D}^{\prime}\right)$.

to GluR2, its trafficking proteins GRIP1, ABP, PICK1, and stargazin disappeared in the light-damage zone (data not shown). In parallel with the loss of GluR2 and its trafficking proteins, dendrites of rod bipolar cells and neurites of horizontal cells in the light-damage zone OPL were retracted and flattened (Figure 6C and 6D). We also observed a horizontal cell body located adjacent to the RPE at the distal border of the remnant ONL (Figure 6D, arrow).

Protein levels of calcium-buffering proteins show no change during LIRD

The major subunits of AMPA receptors, GluR1 and GluR2, play have important roles in neuroplasticity [44]. 


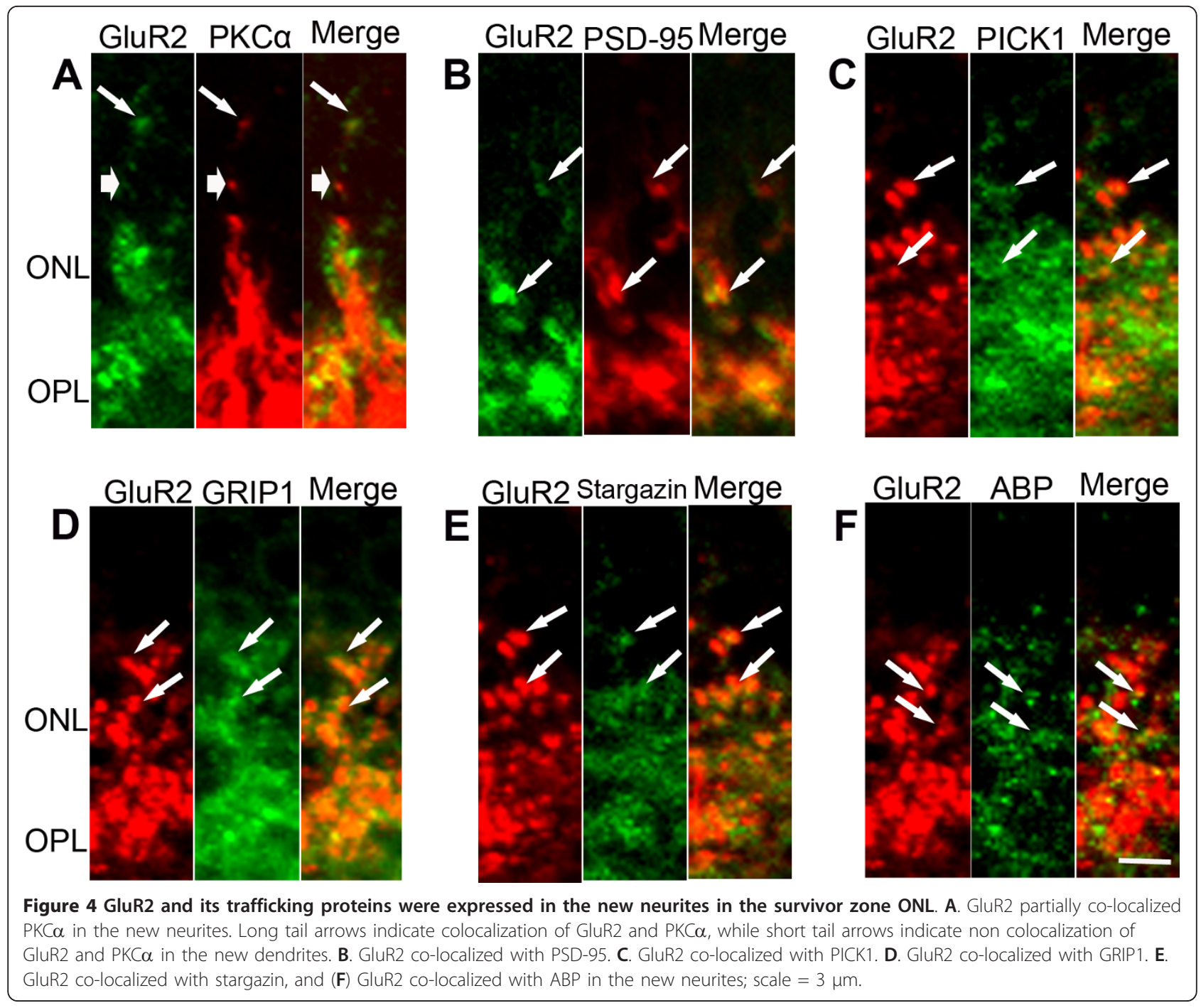

Given that LIRD increased the levels of GluR2, we examined the effect of LIRD on GluR1. Phosphorylation of GluR1 is a major mechanism for controlling excitation. Since our light damage protocol spans the period of photoreceptor stress (increased extracellular glutamate) all the way to complete photoreceptor loss, we deemed it appropriate to screen events known in CNS to modulate excitation. Further, GluR2 binds to PICK1 after phosphorylation at serine 880 by PKC $\alpha$, which induces dissociation of GluR2 from GRIP and the subsequent internalization of GluR2 by PICK1 for recycling or degradation [38]. Thus, we also measured the levels of phosphorylated GluR1 (Ser831) (pGluR1) and phosphorylated GluR2 (Ser880) (pGluR2). Our results revealed that light stress had no significant effect on the protein levels of GluR1 (Figure 7A and 7B). However, light stress rapidly decreased the levels of pGluR1, which showed an obvious decrease on pLX0 and reached a minimum on pLX7 but recovered by pLX30. Light stress also decreased the expression of pGluR2 by pLX0, extending its decrease by pLX30. Two calcium binding proteins, calretinin and calbindin, were also examined but showed no LIRD-induced change in protein expression (Figure 7A and 7B).

\section{Effect of AMPA receptors antagonist NBQX on} neuritogenesis during LIRD

$\mathrm{Ca}^{2+} /$ calmodulin-dependent protein kinase II (CaMKII) senses cytosolic $\mathrm{Ca}^{2+}$ fluxes, which are largely mediated by glutamate-activated AMPA or NMDA receptors in CNS neurons [46]. CaMKII plays a central role in synaptic plasticity, both $\alpha$ - and $\beta$-CaMKII are neuronspecific and expressed in retinal neurons [47]. $\alpha$ CaMKII is activated by high $\mathrm{Ca}^{2+}$ levels, while $\beta$ CaMKII is more sensitive to lower $\mathrm{Ca}^{2+}$ levels, and heteromeric CaMKII $\mathrm{Ca}^{2+}$ responsivity and activity depends on the $\alpha / \beta$ 


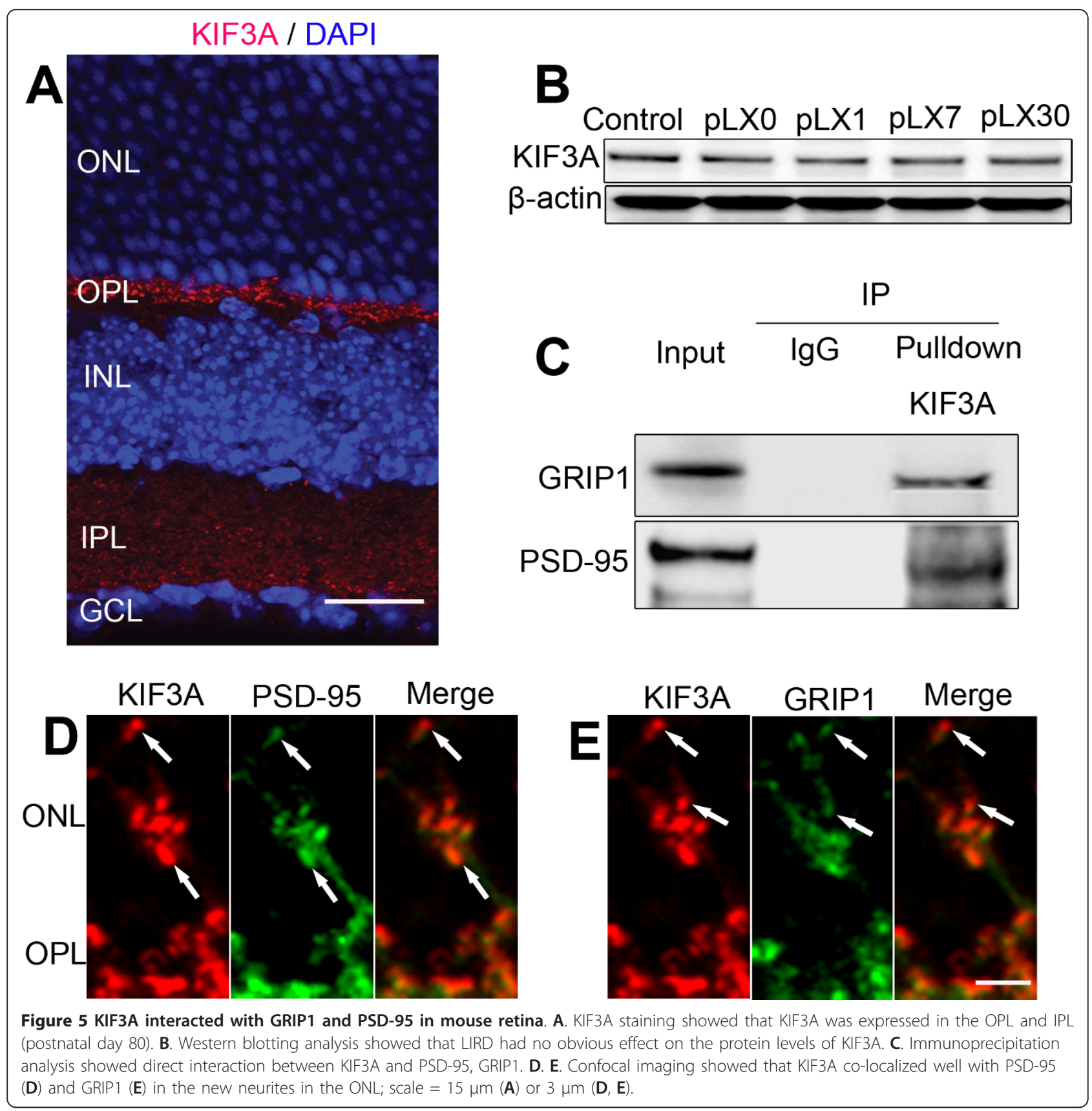

subunit ratio [48]. Decreases in neuronal activity decrease the CaMKII $\alpha / \beta$ ratio, likely by upregulating transcription of $\beta$ CaMKII [49], which positively correlates with the increase in low calcium permeability GluR2 expression in our study. Our previous study revealed that CaMKII plays an important role in neuritogenesis during retinal degeneration [8]. Therefore, we studied the effects of AMPA receptors antagonist NBQX on CaMKII signaling and neuritogenesis. Our results showed that NBQX slightly mitigated neuritogenesis. Consistently, NBQX had no effect on the ratio of $\alpha / \beta$ CaMKII compared with vehicle group during LIRD (Figure 8A, B, and 8D-F). However, NMDA receptors antagonist D-AP5 obviously increased the ratio of $\alpha / \beta C a M K I I$ and significantly accelerated neuritogenesis (Figure 8A, C and 8D-F). Because NBQX is neuroprotective [50] but does not block downregulation of GluR2 [51], our results suggest that NBQX affords neuroprotection by a direct block of GluR2-lacking, $\mathrm{Ca}^{2+}$-permeable AMPA receptors [31]. Due to that GluR1 levels were not altered during LIRD, the above results totally suggest that AMPA receptor GluR2 in particular drives 


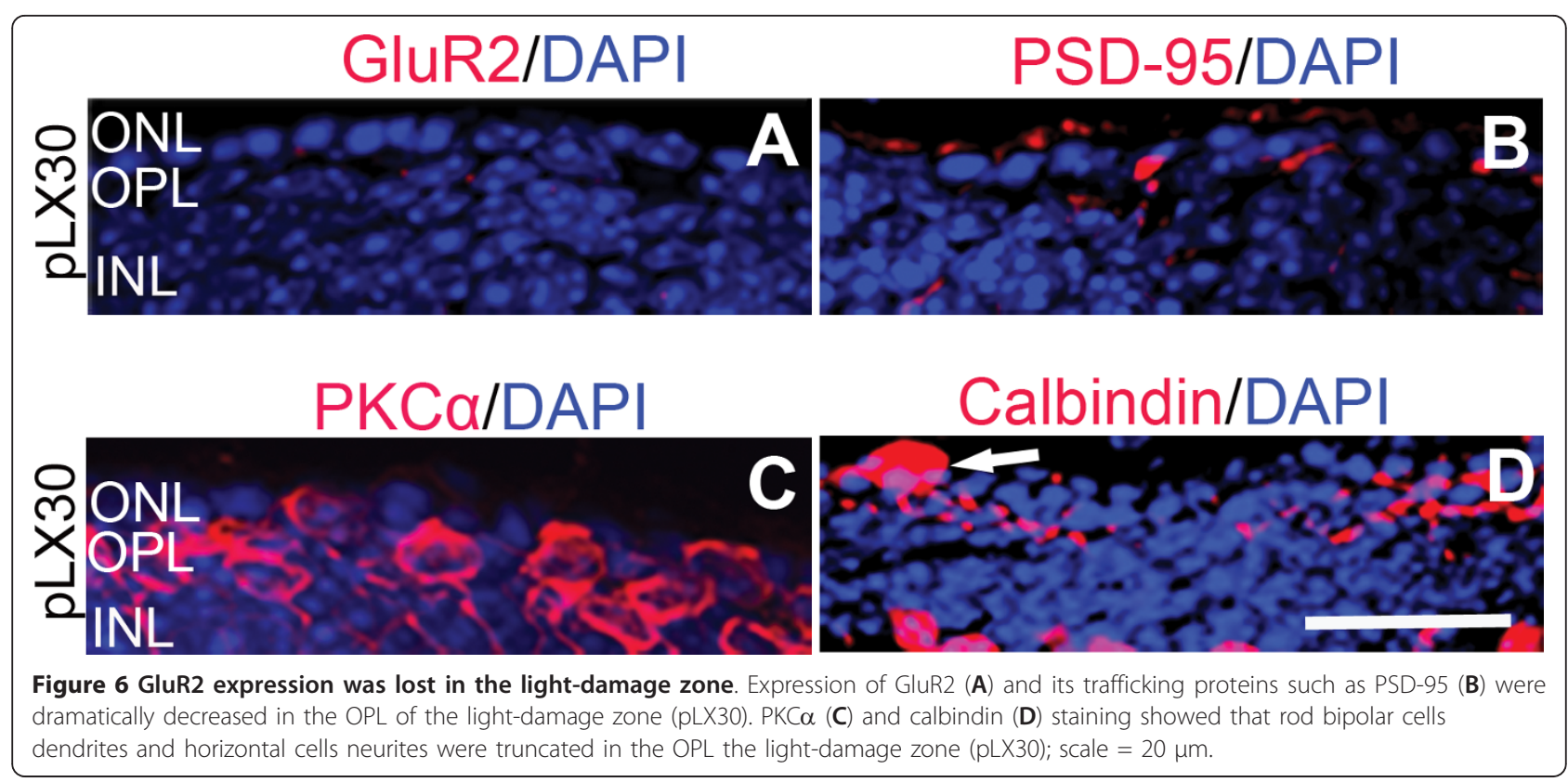

CaMKII signaling associated with neuritogenesis during LIRD.

\section{Discussion}

We reveal a correlation of neurite formation and retraction with changes in expression of GluR2 and GluR2 trafficking machinery in the LIRD model. Alterations in GluR2 expression may provide a feedback mechanism for altering $\mathrm{Ca}^{2+}$ permeability in deafferented retinal neurons, therefore be responsible for de novo neuritogenesis, and ultimately contribute to functional reprogramming of neural circuitry.

Normally, increasing the ratio of GluR2 subunits in iGluRs plays a protective role by decreasing $\mathrm{Ca}^{2+}$ loads in neurons, which likely can not be blocked by AMPA receptors inhibitor NBQX [31]. Additionally, GluR2-mediated decreases in $\mathrm{Ca}^{2+}$ permeability can prevent GluR1 phosphorylation-dependent increases in calcium conductance [52]. In LIRD, GluR1 expression is not changed while GluR1 phosphorylation decreases and levels of calcium-buffering proteins calretinin and calbindin remain stable. Similarly, data from diabetic subjects showed significant retinal increases of GluR2 but not GluR1 immunoreactivity in the OPL and IPL [53-55]. GluR2 upregulation in various retinal disease models suggests that this may be a protective response to photoreceptor-mediated stress and deafferentation.

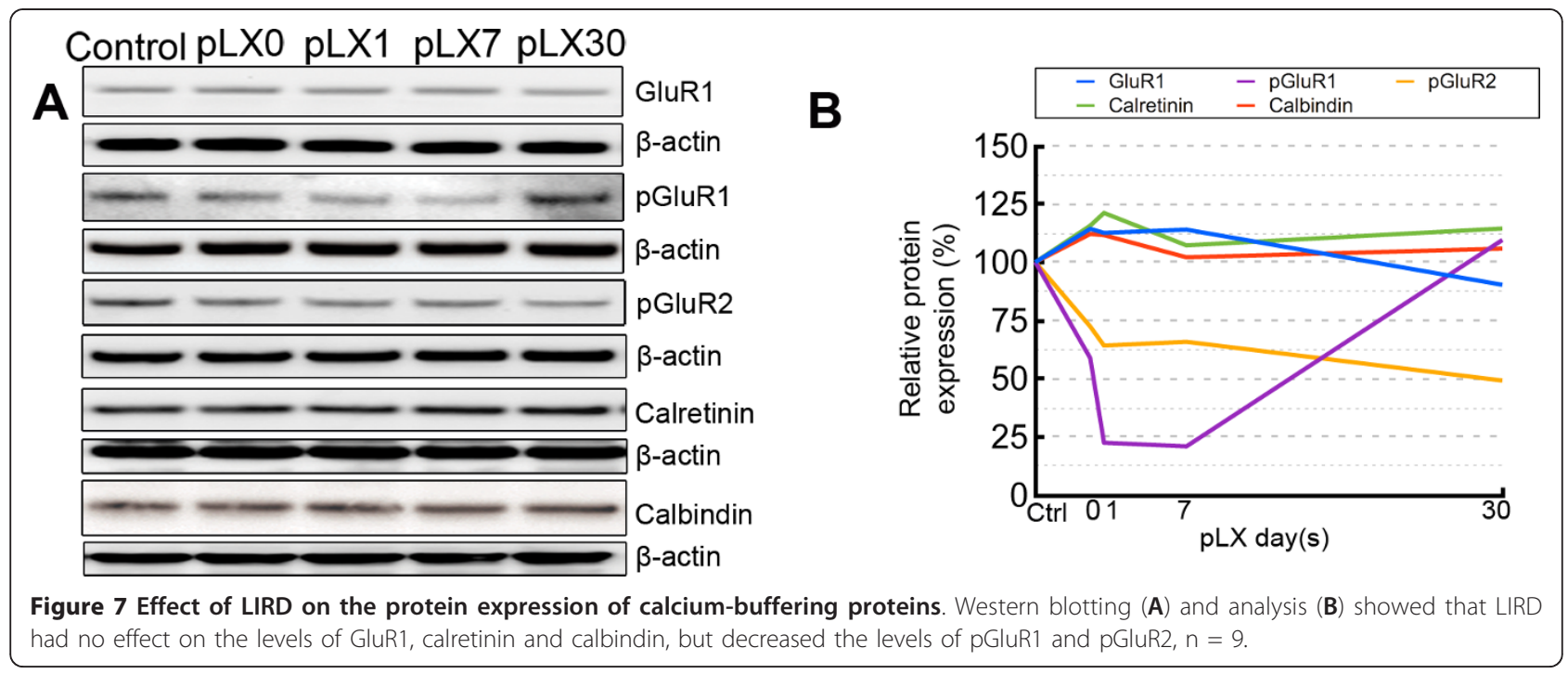




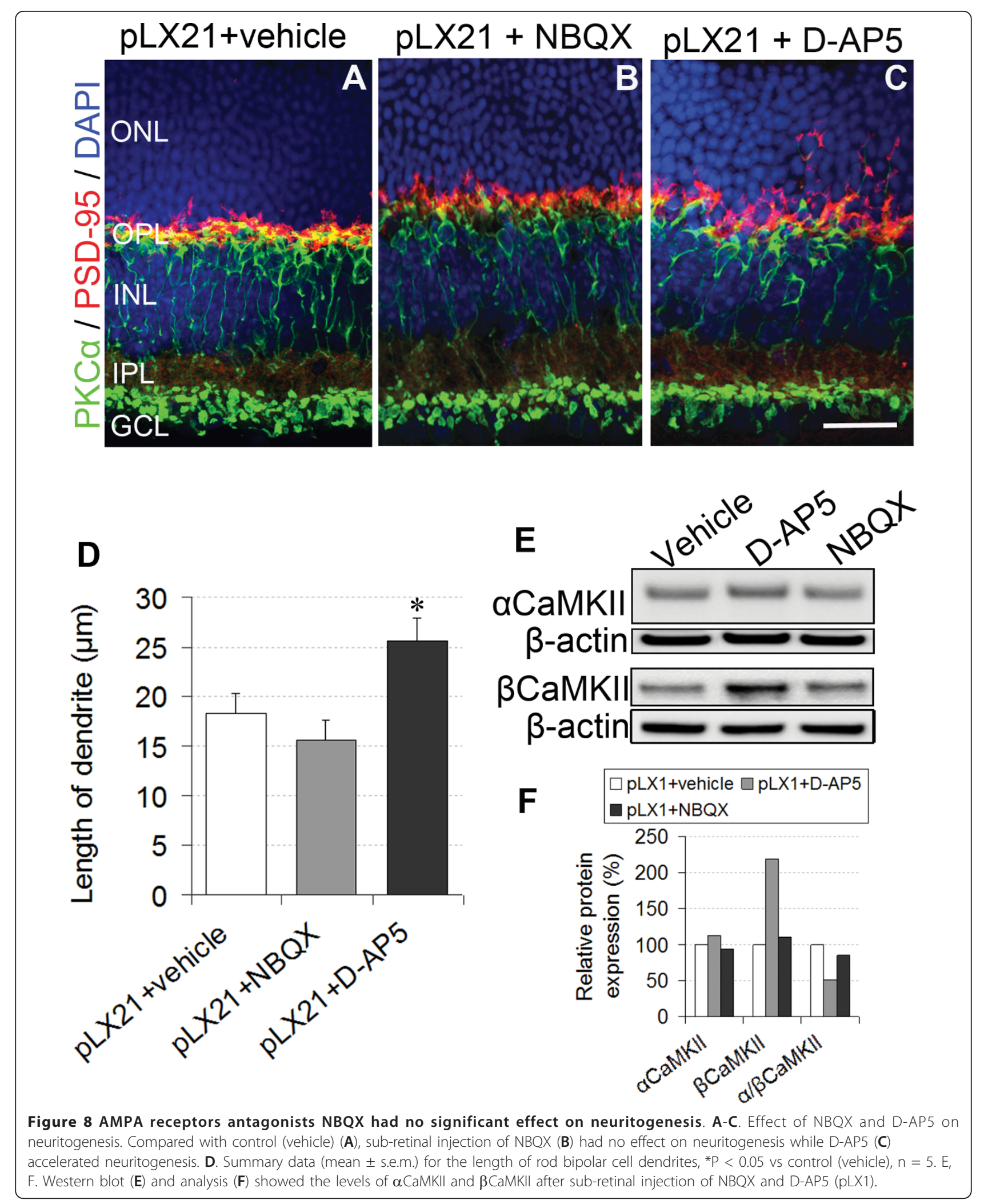


Nevertheless, GluR2 levels (mRNA) were found unchanged in $r d$ mouse retina [56]. Most inherited degenerations are slow compared to light damage and their time profiles are complex [1,2]. Even the fast $r d$ model requires 3 months for all photoreceptors to die and there is no known coherent stress period (at least we don't know if anyone has published such an analysis). Light damage has a very precise onset of a few hours. The 1995 Duvoison paper [56] does not specify the time point at which the $35 \mathrm{~S}$ GluR ISH autoradiographic measurements were made. As shown by Jones et al. [13,57], Marc et al. [1,2,4,12], RD (including light damage) have complex time profiles and pass through three distinct phases: phase 1 (photoreceptor stress and early death), phase 2 (active photoreceptor death), phase 3 (remodeling after all photoreceptors are lost). Our examination of that paper suggests that the $r d$ animals were adult, in which case they were in late phase 3 remodeling and the outer retina was completely decimated, lacking bipolar cell and horizontal cell dendrites. The purpose of our current paper was to profile the kinetics of glutamate receptors before such a pathologic state. Indeed our results show that the major changes in GluR expression occur acutely during phase 1 of light damage and quickly normalize, suggesting that GluR2 modulation is acute.

GluR2-mediated changes in $\mathrm{Ca}^{2+}$ permeability may be also responsible for the subsequent neurite outgrowth of retinal neurons. In embryonic chick retinal neurons, early activation of $\mathrm{Ca}^{2+}$-permeable AMPA receptors reduces neurite outgrowth [58], and influx of $\mathrm{Ca}^{2+}$ through these channels could be responsible for the reduction in neurite outgrowth of cultured hippocampal pyramidal cells [59]. GluR2 co-localizing with its trafficking proteins PICK1, ABP, GRIP1 and stargazin at new neurites during LIRD suggests that this same mechanism may be represented in deafferented retina. The interaction of stargazin with AMPA receptors is essential for delivering functional receptors to the surface membrane, whereas binding with PSD-95, a GluR-clustering molecule, is required for targeting the AMPA receptors to synapses [60]. During GluR2 trafficking, the PICK1-ABP/GRIP interaction targets PICK1-PKC $\alpha$ complexes to ABP/GRIP-AMPA receptor complexes. GluR2 binds to PICK1 after phosphorylation at serine 880 by PKC $\alpha$, which induces dissociation of GluR2 from GRIP and the subsequent internalization of GluR2 by PICK1 for recycling or degradation [38]. Therefore, rapid alterations in GluR2 and its trafficking during early LIRD may reveal mechanisms to limit $\mathrm{Ca}^{2+}$-mediated damage or simply reflect loss of dendritic iGluRs as dendrites are lost $[4,13]$. Normalization of GluR2 expression by pLX30 may reveal new GluR2 expression in novel dendrites that are in the process of forming new synaptic complexes.
This study demonstrates that expression of GluR2 and its trafficking proteins in the new dendrites may be guided through KIF3A, a member of the heteromeric family of kinesins which constitute a large family of microtubule motor proteins [45]. In neurons, kinesin motors conduct transport to axons and neurotransmitter receptors to dendrites and GRIP1 directly interacts with kinesin enabling transport of dendritic proteins such as GluR2 [61]. Our work reveals the expression of KIF3A in the OPL, where is dominated by ribbon synapses between presynaptic photoreceptors and postsynaptic horizontal cells and bipolar cells, both of which are involved in early reactive neuritogenesis in the degenerative retina. Interaction between KIF3A and GRIP1 and PSD-95 indicates that KIF3A has the potential to steer GRIP1 and PSD-95 to the new dendritic formation. Because GluR2 and its trafficking proteins are anchored with PSD-95, it is possible that GluR2 and its trafficking proteins are guided indirectly by PSD-95 and GRIP1 to the new processes.

In normal tissues, differential expression of GluRs by bipolar cells creates parallel ON and OFF channels in vision. ON bipolar cells express mGluR6 receptors while OFF bipolar cells express either AMPA or KA receptors. In retinal degenerative diseases, the observation of GluR2 in pathological newly-formed bipolar cell dendrites is a new finding and likely contributes to the functional reprogramming observed in bipolar cells of degenerative retina $[4,13]$. Altered differential expression of GluRs by bipolar cells explains the phenotypic revision and reprogramming of bipolar cells observed in RD $[7,12,13]$. Previously, we demonstrated phenotypic plasticity in human RP and in animal models of cone-sparing RP where loss of rods, but not cones, leads to phenotype revision, inducing a switch from $\mathrm{ON}$ to OFF phenotypes in rod bipolar cells [4]. Nevertheless, primate ON bipolar cells also express a cohort of AMPA receptor genes in normal retina [62] and GluR2 subunits have long been identified in rod bipolar cells $[21,26,28,55,63]$. The fact that normal rod bipolar cells express iGluR subunits argues that such switching may be within the normal capacity of bipolar cells [4].

\section{Conclusions}

In summary, this work is the first to study GluR2 and its trafficking proteins during RD. Our findings suggest that rapid alteration of GluR2 trafficking/regulation is involved in pathological neuritogenesis and is a potential mechanism behind phenotypic reprogramming of retinal neurons. Modulation of GluR2 expression and its trafficking may slow down primary neurite remodeling or limit neuritogenesis. However, further research is needed to separate the GluR2-mediated pathways that contribute to neuroprotection and pathological neuritogenesis. 


\section{Methods \\ Animals}

Age-matched female Balb/C albino mice (The Jackson Laboratory, Bar Harbor, ME) were maintained in dim light (20-40 lux) on a 12-12 cycle in normal phase (lights on 7:00-19:00) with ad libitum access to food and water. All experimental procedures were designed to minimize animal number and suffering, and were conducted with approval of the Institutional Animal Care Committees at the University of Utah in accordance with the ARVO Statement for the Use of Animals in Ophthalmic and Vision Research.

\section{LIRD and subretinal injections}

LIRD and subretinal injections were performed as described previously [8]. In brief, mice were placed into the light-damage chamber, where the visible light intensity ranged from 2,500 to 3,000 lux, for 24 h by excluding one normal night cycle. Following post-light exposure (pLX), all animals were returned to the dim cyclic light environment and maintained for $0,1,7$, and 30 days ( $\mathrm{pLX} 0, \mathrm{pLX} 1, \mathrm{pLX} 7$, and $\mathrm{pLX} 30$ ). Under ketamine-xylazine anesthesia, $5 \mu \mathrm{M}$ NBQX (Sigma, St. Louis, MO, USA) and $50 \mu \mathrm{M}$ D-AP5 (Sigma) were injected into the sub-retinal space (central region) of albino mice in $0.5 \mu \mathrm{l}$ volumes using a 33 -gauge micro syringe (Hamilton) 30 min before light exposure. A successful sub-retinal injection caused swelling of the retina. Control retinas were injected with vehicle (DMSO) (Sigma).

\section{Sample processing}

At the end of the experiment, eyes were rapidly harvested following decapitation under isoflurane anesthesia. For Western blotting analysis, retinas were dissected in Hank's balanced salt solution (HBSS, GIBCO, Carlsbad, CA, USA), then placed on ice in $1.5 \mathrm{ml}$ tubes with RIPA buffer (RIPA lysis buffer kit, Santa Cruz, CA, USA) and homogenized using a sonicator (Fisher Scientific, Pittsburgh, PA, USA) three times for $12 \mathrm{sec}$ each with $12 \mathrm{sec}$ breaks between cycles. The samples were put on ice for $10 \mathrm{~min}$, then centrifuged at $14,000 \mathrm{rpm}$ at $4^{\circ} \mathrm{C}$ for 10 min. Supernatants were transferred to new tubes. The concentrations of protein in the samples were measured using the BCA assay (Pierce, Rockford, IL USA). For immunohistochemical analysis, whole eyes were removed and rinsed in HBSS, fixed in $4 \%$ paraformaldehyde (PFA) (Sigma) for $2 \mathrm{~h}$ at $4^{\circ} \mathrm{C}$, and then washed with PBS (in g/L: $\mathrm{NaCl}$ 8, $\mathrm{KCl} 0.2, \mathrm{Na}_{2} \mathrm{HPO}_{4}$ 1.44, $\mathrm{KH}_{2} \mathrm{PO}_{4}$ 0.24; pH 7.4) twice for $10 \mathrm{~min}$ each. Eyes were incubated in PBS with $20 \%$ sucrose for $4 \mathrm{~h}$ at $4^{\circ} \mathrm{C}$. Serial $12 \mu \mathrm{m}$ coronal sections were made with a cryostat microtome (Leica CM3050 S,
Wetzlar, Germany) and collected on Superfrost/plus microscope slides (Fisher Scientific).

\section{Immunoprecipitation}

Retinas were lysed in RIPA buffer (RIPA lysis buffer kit, Santa Cruz) for $1 \mathrm{~h}$ at $4^{\circ} \mathrm{C}$ with gentle agitation. Lysates were immunoprecipitated for $1 \mathrm{~h}$ at $4^{\circ} \mathrm{C}$ using KIF3A antibody (1:1000) and then protein $\mathrm{G}$ agarose beads (Roche, Indianapolis, IN, USA) [8]. Samples were analyzed by Western blotting.

\section{Western blotting analysis}

Samples of entire group were pooled. Protein samples $(\sim 20 \mu$ g protein) were combined with NuPAGE LDS sample buffer $(4 \times)$ (Invitrogen, Carlsbad, CA, USA) and NuPAGE sample reducing agent $(10 \times)$ (Invitrogen), then boiled for $10 \mathrm{~min}$ at $95^{\circ} \mathrm{C}$. Western blotting analysis was carried out using NuPAGE 4-12\% Bis-Tris gels (Invitrogen) at $200 \mathrm{~V}$ for $40 \mathrm{~min}$. Gels were electro-blotted onto PVDF membrane (Millipore, Bedford, MA, USA) for $1 \mathrm{~h}$ at $25 \mathrm{~V}$ using a wet electro-blotting system (XCell SureLock Mini-Cell, Invitrogen). Blots were blocked for $1 \mathrm{~h}$ in PBS with 0.1\% Triton-x100, $\mathrm{pH} 7.4$ (PBST) containing 5\% non-fat dry milk (NFDM). Blots then were incubated overnight at $4^{\circ} \mathrm{C}$ in primary antibodies diluted in 5\% NFDM-PBST solution (GluR2, 1:1000, Chemicon; pGluR2, 1:1000, Millipore; protein kinase C $\alpha$ (PKC $\alpha), 1: 5000$, Sigma; GluR1, 1:2000, Upstate; pGluR1, 1:1000, Millipore; PSD-95, 1:500, Chemicon; protein interacting with $\mathrm{C}$ kinase 1 (PICK1), 1:400, Santa Cruz; GRIP1, 1:1000, Millipore; stargazin, 1:500, Chemicon; AMPA receptor binding protein (ABP), 1:400, Santa Cruz; KIF3A, 1:1000, Covance; calretinin, 1:2000, Abcam; calbindin, 1:2000, Abcam; $\alpha$ CaMKII 1:1000, Upstate; $\beta$ CaMKII: 1:1000, Invitrogen). Blots were washed three times for $10 \mathrm{~min}$ in PBST, incubated for $2 \mathrm{~h}$ in secondary antibodies (IgG-HRP, Santa Cruz; 1:5000 in 5\% NFDM-PBST) followed by three more washes of $10 \mathrm{~min}$ in PBST. Immunostaining was revealed by the SuperSignal West Dura Extended Duration Substrate kit (Thermo Scientific, Waltham, MA, USA), and scanned using the Quantity One imaging system (Bio-Rad). Densitometry for each band was measured using ImageJ (U.S. National Institutes of Health, Bethesda, MD, USA). $\beta$-actin (1:5000, Sigma) was used as a loading control.

\section{Immunohistochemistry}

Cryosections were washed $2 \times 10$ min in PBS, then blocked with blocking buffer for $30 \mathrm{~min}$. Cryosections were incubated overnight at $4{ }^{\circ} \mathrm{C}$ in primary antibodies diluted in blocking buffer (GluR2, 1:500, Chemicon or 
1:200, Santa Cruz; PKC $\alpha$, 1:2000; PSD-95, 1:500; PICK1, 1:200; GRIP1, 1:500; stargazin, 1:500; ABP, 1:100; KIF3A, 1:500; calbindin, 1:1000). These primary antibodies were from different species in every case and they did not cross-react on Western Blots. After washing $3 \times$ $10 \mathrm{~min}$ in PBS, sections were incubated for $45 \mathrm{~min}$ at room temperature in secondary antibodies (cy3-, 488or 647-conjugated IgG, Invitrogen) diluted 1:1000 in blocking buffer. For double or triple staining, sections were sequentially incubated with primary antibodies and secondary antibodies as above. After incubation with antibodies, sections were washed $3 \times 10 \mathrm{~min}$ in PBS, then treated with $10 \mu \mathrm{M}$ DAPI (Invitrogen) for $5 \mathrm{~min}$ at room temperature. Sections from all groups were processed simultaneously to reduce staining artifacts or intensity differences. Negative controls were performed by omission of the primary antibodies.

\section{Confocal imaging}

Fluorescent images were acquired with an Olympus FV1000 laser-scanning confocal microscope (Olympus, Tokyo, Japan). Settings were chosen so that pixel intensities for the brightest samples were just below saturation, except when the processes of retinal neurons had to be clearly determined, in which case signals from certain areas (soma of the retinal neurons) were saturated in order to obtain a clear perimeter of the neurites. Optical slice units were 0.5 $\mu \mathrm{m}$. Neuritogenesis was analyzed as described [8]. In brief, neurite length was measured from the point of emergence at the cell body to the tip of each segment. One section was selected from each animal, and 20 longest dendrites from 20 rod bipolar cells in a specific region (ventral midperipheral region, $120 \mu \mathrm{m}$ in length) were measured and calculated as the mean. Quantification of the morphological parameters was carried out using ImageJ by investigators blinded to experimental conditions.

\section{Data analysis}

Data of neuritogenesis were expressed as mean \pm SD and analyzed with SPSS 12.0 (SPSS Inc.). Statistical comparisons were made using Bonferroni tests and analysis of variance (ANOVA), $\mathrm{P}<0.05$ was defined as the level of significance. Protein levels represented pooled data of entire groups and were expressed as means only. To study the rationality of pooling samples in our experiment, we actually set up 3 batches of animals. There were 3 mice per group in each batch (i.e. 9 mice in total for each group). We pooled the 3 mice's retinas from each group in each batch and ran the western blotting for protein analysis. It was found that the biological variations for the 9 mice were low and GluR2 increase, for example, was significant during early LIRD (Additional file 1 Figure S1).

\section{Additional material}

\section{Additional file 1: Figure S1. Rationality of pooling samples in our}

experiment.

\section{Abbreviations}

LIRD: light-induced retinal degeneration; AMD: age-related macular degeneration; RP: retinitis pigmentosa; pLX: post-light exposure; GluRs: glutamate receptors; GluR2: glutamate receptor 2; pGluR2: phosphorylation of glutamate receptor 2; CaMKIl: $\mathrm{Ca}^{2+} /$ calmodulin-dependent protein kinase II; PKCa: protein kinase C a; GRIP1: glutamate receptor-interacting protein 1; PSD-95: postsynaptic density protein 95; KIF3A: kinesin family member 3A; ABP: AMPA receptor binding protein; PICK1: protein interacting with $C$ kinase 1; RPE: retinal pigment epithelium; OPL: outer plexiform layer; ONL: outer nuclear layer; INL: inner nuclear layer; AMPA: a-amino-3-hydroxy-5methyl-4-isoxazolepropionic acid; NMDA: N-methyl-D-aspartate.

\section{Acknowledgements}

This project was supported by NIH EY002576 (REM), EY015128 (REM), EY014800 Vision Core (REM), Research to Prevent Blindness (REM), Signature Immunologics (REM), Edward N. and Della L. Thome Memorial Foundation grant for Age-Related Macular Degeneration Research (BWJ), a Research to Prevent Blindness Career Development Award (BWJ), Moran Eye Center Tiger Team Translational Medicine Award (BWJ), Fight For Sight (YHL, FRVC and WDF), Knights Templar Eye Foundation (YHL and FRVC), 5T32 HD07491 (FRVC), International Retinal Research Foundation (YHL, FRVC), and an unrestricted grant from Research to Prevent Blindness to the Moran Eye Center. We thank Kevin Rapp, Marguerite V. Shaw, Jia-Hui Yang, and Carl B. Watt for assistance on tissue handling and immunohistochemistry. We thank Dr. Changjiang Zou for assistance on immunoprecipitation.

\section{Authors' contributions}

YHL conceived and designed experiments, either performed or participated in all experiments, analyzed data, and wrote the manuscript; REM conceived experiments, analyzed data, and revise the manuscript; BWJ and AHL performed LIRD, analyzed data and revised the manuscript; FRV, JSL and WDF revised the manuscript. All authors have read and approved the final manuscript.

\section{Competing interests}

The authors declare that they have no competing interests.

Received: 27 November 2011 Accepted: 10 February 2012

Published: 10 February 2012

\section{References}

1. Marc RE, Jones BW: Retinal remodeling in inherited photoreceptor degenerations. Mol Neurobiol 2003, 28:139-147.

2. Marc RE, Jones BW, Watt CB, Strettoi E: Neural remodeling in retinal degeneration. Prog Retin Eye Res 2003, 22:607-655.

3. Jones BW, Marc RE: Retinal remodeling during retinal degeneration. Exp Eye Res 2005, 81:123-137.

4. Marc RE, Jones BW, Anderson JR, Kinard K, Marshak DW, Wilson JH, Wensel T, Lucas RJ: Neural reprogramming in retinal degeneration. Invest Ophthalmol Vis Sci 2007, 48:3364-3371.

5. Sullivan RK, Woldemussie E, Pow DV: Dendritic and synaptic plasticity of neurons in the human age-related macular degeneration retina. Invest Ophthalmol Vis Sci 2007, 48:2782-2791.

6. Strettoi E, Porciatti V, Falsini B, Pignatelli V, Rossi C: Morphological and functional abnormalities in the inner retina of the $\mathrm{rd} / \mathrm{rd}$ mouse. $J$ Neurosci 2002, 22:5492-5504.

7. Dagnelie G: Visual prosthetics: physiology, bioengineering, rehabilitation. New York: Springer; 2011.

8. Lin Y, Jones BW, Liu A, Tucker JF, Rapp K, Luo L, Baehr W, Bernstein PS, Watt CB, Yang JH, Shaw MV, Marc RE: Retinoid receptors trigger neuritogenesis in retinal degenerations. FASEB J 2012, 26:81-92.

9. Morimoto K, Fahnestock M, Racine RJ: Kindling and status epilepticus models of epilepsy: rewiring the brain. Prog Neurobiol 2004, 73(1):1-60. 
10. Scheibel AB, Tomiyasu U: Dendritic sprouting in Alzheimer's presenile dementia. Exp Neurol 1978, 60(1):1-8.

11. Dejneka NS, Rex TS, Bennett J: Gene therapy and animal models for retinal disease. Dev Ophthalmol 2003, 37:188-198.

12. Marc RE, Jones BW, Watt CB, Vazquez-Chona F, Vaughan DK, Organisciak DT: Extreme retinal remodeling triggered by light damage: implications for age related macular degeneration. Mol Vis 2008, 14:782-806.

13. Jones BW, Kondo M, Terasaki H, Watt CB, Rapp K, Anderson J, Lin Y, Shaw MV, Yang JH, Marc RE: Retinal remodeling in the TgP347L rabbit, a large-eye model of retinal degeneration. J Comp Neurol 2011, 519:2713-2733.

14. Peng YW, Hao Y, Petters RM, Wong F: Ectopic synaptogenesis in the mammalian retina caused by rod photoreceptor-specific mutations. Nat Neurosci 2000, 3:1121-1127.

15. Barhoum R, Martinez-Navarrete G, Corrochano S, Germain F, FernandezSanchez L, de la Rosa EJ, de la Villa P, Cuenca N: Functional and structural modifications during retinal degeneration in the $\mathrm{rd} 10$ mouse. Neuroscience 2008, 155:698-713.

16. Malinow R, Malenka RC: AMPA receptor trafficking and synaptic plasticity. Annu Rev Neurosci 2002, 25:103-126.

17. Rosenmund C, Stern-Bach Y, Stevens CF: The tetrameric structure of a glutamate receptor channel. Science 1998, 280:1596-1599.

18. Liu SJ, Cull-Candy SG: Subunit interaction with PICK and GRIP controls Ca2+ permeability of AMPARs at cerebellar synapses. Nat Neurosci 2005 8:768-775.

19. Lankford KL, Letourneau PC: Evidence that calcium may control neurite outgrowth by regulating the stability of actin filaments. Journal Cell Biol 1989, 109:1229-1243

20. Zucker RS: Calcium- and activity-dependent synaptic plasticity. Curr Opin Neurobiol 1999, 9:305-313.

21. Grunert U, Haverkamp S, Fletcher EL, Wassle H: Synaptic distribution of ionotropic glutamate receptors in the inner plexiform layer of the primate retina. J Comp Neurol 2002, 447:138-151.

22. Hollmann M, Hartley M, Heinemann S: Ca2+ permeability of KA-AMPAgated glutamate receptor channels depends on subunit composition. Science 1991, 252:851-853.

23. Geiger JR, Melcher T, Koh DS, Sakmann B, Seeburg PH, Jonas P, Monyer $H$ : Relative abundance of subunit mRNAs determines gating and $\mathrm{Ca} 2+$ permeability of AMPA receptors in principal neurons and interneurons in rat CNS. Neuron 1995, 15:193-204.

24. Liu SJ, Zukin RS: Ca2+-permeable AMPA receptors in synaptic plasticity and neuronal death. Trends Neurosci 2007, 30:126-134.

25. Chua J, Fletcher EL, Kalloniatis M: Functional remodeling of glutamate receptors by inner retinal neurons occurs from an early stage of retinal degeneration. Journal Comp Neurol 2009, 514:473-491.

26. Hughes $T E$, Hermans-Borgmeyer I, Heinemann S: Differential expression of glutamate receptor genes (GluR1-5) in the rat retina. Vis Neurosci 1992, 8:49-55.

27. Ghosh KK, Haverkamp S, Wassle H: Glutamate receptors in the rod pathway of the mammalian retina. J Neurosci 2001, 21:8636-8647.

28. Kamphuis W, Klooster J, Dijk F: Expression of AMPA-type glutamate receptor subunit (GluR2) in ON-bipolar neurons in the rat retina. J Comp Neurol 2003, 455:172-186

29. Burnashev N, Khodorova A, Jonas P, Helm PJ, Wisden W, Monyer H, Seeburg PH, Sakmann B: Calcium-permeable AMPA-kainate receptors in fusiform cerebellar glial cells. Science 1992, 256:1566-1570.

30. Tanaka H, Calderone A, Jover T, Grooms SY, Yokota H, Zukin RS, Bennett MV: Ischemic preconditioning acts upstream of GluR2 downregulation to afford neuroprotection in the hippocampal CA1. Proc Nat Acad Sci USA 2002, 99:2362-2367.

31. Gorter JA, Petrozzino JJ, Aronica EM, Rosenbaum DM, Opitz T, Bennett MV Connor JA, Zukin RS: Global ischemia induces downregulation of Glur2 mRNA and increases AMPA receptor-mediated $\mathrm{Ca} 2+$ influx in hippocampal CA1 neurons of gerbil. J Neurosci 1997, 17:6179-6188.

32. Vaughan DK, Coulibaly SF, Darrow RM, Organisciak DT: A morphometric study of light-induced damage in transgenic rat models of retinitis pigmentosa. Invest Ophthalmol Vis Sci 2003, 44:848-855.

33. Okabe S: Molecular anatomy of the postsynaptic density. Mol Cell Neurosci 2007, 34:503-518.
34. Dong H, O'Brien RJ, Fung ET, Lanahan AA, Worley PF, Huganir RL: GRIP: a synaptic PDZ domain-containing protein that interacts with AMPA receptors. Nature 1997, 386:279-284.

35. Xia J, Zhang X, Staudinger J, Huganir RL: Clustering of AMPA receptors by the synaptic PDZ domain-containing protein PICK1. Neuron 1999, 22:179-187.

36. Sheng M, Hoogenraad CC: The postsynaptic architecture of excitatory synapses: a more quantitative view. Annu Rev Biochem 2007, 76:823-847.

37. Tomita S, Chen L, Kawasaki Y, Petralia RS, Wenthold RJ, Nicoll RA, Bredt DS: Functional studies and distribution define a family of transmembrane AMPA receptor regulatory proteins. J Cell Biol 2003, 161:805-816.

38. Lu W, Ziff EB: PICK1 interacts with ABP/GRIP to regulate AMPA receptor trafficking. Neuron 2005, 47:407-421.

39. Koulen P, Fletcher EL, Craven SE, Bredt DS, Wassle H: Immunocytochemical localization of the postsynaptic density protein PSD-95 in the mammalian retina. J Neurosci 1998, 18:10136-10149.

40. Gabriel R, de Souza S, Ziff EB, Witkovsky P: Association of the AMPA receptor-related postsynaptic density proteins GRIP and ABP with subsets of glutamate-sensitive neurons in the rat retina. J Comp Neurol 2002, 449:129-140.

41. Strettoi E, Pignatelli V: Modifications of retinal neurons in a mouse model of retinitis pigmentosa. Proc Natl Acad Sci USA 2000, 97:11020-11025.

42. Park SJ, Kim IB, Choi KR, Moon JI, Oh SJ, Chung JW, Chun MH: Reorganization of horizontal cell processes in the developing FVB/N mouse retina. Cell Tissue Res 2001, 306:341-346.

43. Fariss RN, Li ZY, Milam AH: Abnormalities in rod photoreceptors, amacrine cells, and horizontal cells in human retinas with retinitis pigmentosa. Am J Ophthalmol 2000, 129:215-223.

44. Du J, Creson TK, Wu LJ, Ren M, Gray NA, Falke C, Wei Y, Wang Y, Blumenthal R, Machado-Vieira R, Yuan P, Chen G, Zhuo M, Manji HK: The role of hippocampal GluR1 and GluR2 receptors in manic-like behavior. J Neurosci 2008, 28:68-79.

45. Muresan V, Lyass A, Schnapp BJ: The kinesin motor KIF3A is a component of the presynaptic ribbon in vertebrate photoreceptors. J Neurosci 1999, 19:1027-1037.

46. Rongo C, Kaplan JM: CaMKII regulates the density of central glutamatergic synapses in vivo. Nature 1999, 402:195-199.

47. Liu LO, Li G, McCall MA, Cooper NG: Photoreceptor regulated expression

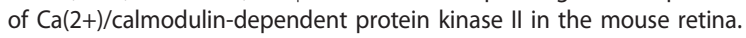
Brain Res Mol Brain Res 2000, 82:150-166.

48. De Koninck P, Schulman H: Sensitivity of CaM kinase II to the frequency of Ca2+ oscillations. Science 1998, 279:227-230.

49. Thiagarajan TC, Piedras-Renteria ES, Tsien RW: alpha- and betaCaMKII. Inverse regulation by neuronal activity and opposing effects on synaptic strength. Neuron 2002, 36:1103-1114.

50. Sheardown MJ, Nielsen EO, Hansen AJ, Jacobsen P, Honore T: 2,3Dihydroxy-6-nitro-7-sulfamoyl-benzo(F)quinoxaline: a neuroprotectant for cerebral ischemia. Science 1990, 247:571-574.

51. Pellegrini-Giampietro DE, Pulsinelli WA, Zukin RS: NMDA and non-NMDA receptor gene expression following global brain ischemia in rats: effect of NMDA and non-NMDA receptor antagonists. J Neurochem 1994, 62:1067-1073.

52. Liu S, Lau L, Wei J, Zhu D, Zou S, Sun HS, Fu Y, Liu F, Lu Y: Expression of $\mathrm{Ca}(2+)$-permeable AMPA receptor channels primes cell death in transient forebrain ischemia. Neuron 2004, 43:43-55.

53. Ng YK, Zeng XX, Ling EA: Expression of glutamate receptors and calciumbinding proteins in the retina of streptozotocin-induced diabetic rats. Brain Res 2004, 1018:66-72.

54. Santiago AR, Hughes JM, Kamphuis W, Schlingemann RO, Ambrosio AF: Diabetes changes ionotropic glutamate receptor subunit expression level in the human retina. Brain Res 2008, 1198:153-159.

55. Semkova I, Huemmeke M, Ho MS, Merkl B, Abari E, Paulsson M, Joussen AM, Plomann M: Retinal localization of the glutamate receptor GluR2 and GluR2-regulating proteins in diabetic rats. Exp Eye Res 2010, 90:244-253.

56. Duvoisin RM, Zhang C, Hamassaki-Britto DE, Britto LR: Changes in expression of glutamate receptor subunits following photoreceptor degeneration in the rd mouse retina. Neurosci Lett 1995, 183:83-86.

57. Jones BW, Watt CB, Frederick JM, Baehr W, Chen CK, Levine EM, Milam AH, Lavail MM, Marc RE: Retinal remodeling triggered by photoreceptor degenerations. J Comp Neurol 2003, 464:1-16. 
58. Catsicas M, Allcorn S, Mobbs P: Early activation of $\mathrm{Ca}(2+)$-permeable AMPA receptors reduces neurite outgrowth in embryonic chick retinal neurons. J Neurobiol 2001, 49:200-211.

59. Mattson MP, Dou P, Kater SB: Outgrowth-regulating actions of glutamate in isolated hippocampal pyramidal neurons. J Neurosci 1988, 8:2087-2100.

60. Kennedy MB: Signal-processing machines at the postsynaptic density. Science 2000, 290:750-754.

61. Setou M, Seog DH, Tanaka Y, Kanai Y, Takei Y, Kawagishi M, Hirokawa N: Glutamate-receptor-interacting protein GRIP1 directly steers kinesin to dendrites. Nature 2002, 417:83-87.

62. Hanna MC, Calkins DJ: Expression of genes encoding glutamate receptors and transporters in rod and cone bipolar cells of the primate retina determined by single-cell polymerase chain reaction. Mol Vis 2007, 13:2194-2208

63. Hack I, Frech M, Dick O, Peichl L, Brandstatter JH: Heterogeneous distribution of AMPA glutamate receptor subunits at the photoreceptor synapses of rodent retina. Eur J Neurosci 2001, 13:15-24.

doi:10.1186/1750-1326-7-7

Cite this article as: Lin et al:: Rapid glutamate receptor 2 trafficking during retinal degeneration. Molecular Neurodegeneration 2012 7:7.

\section{Submit your next manuscript to BioMed Central} and take full advantage of:

- Convenient online submission

- Thorough peer review

- No space constraints or color figure charges

- Immediate publication on acceptance

- Inclusion in PubMed, CAS, Scopus and Google Scholar

- Research which is freely available for redistribution

Submit your manuscript at www.biomedcentral.com/submit
C Biomed Central 